\title{
A INTERFERÊNCIA DA POLISSEMIA DO VERBO FAZER EM SENTENÇAS CAUSATIVAS: UMA ANÁLISE LINGUÍSTICA E COGNITIVA
}

\author{
Glenda Aparecida Queiroz Milanio ${ }^{1}$ \\ Wasney de Almeida Ferreira ${ }^{2}$
}

\section{RESUMO}

O objetivo deste artigo foi investigar se a polissemia do verbo fazer influencia na frequência de sentenças causativas (analíticas e semi-analíticas) construídas com esse verbo, tendo como aporte teórico os pressupostos da Linguística Teórica. Para isso, aplicamos o teste estatístico qui-quadrado, bem como o coeficiente de contingência modificado, visando a comparar o verbo causativo fazer (por ser mais polissêmico) com outros verbos causativos menos polissêmicos (assegurar, causar, cuidar, provar e provocar). As análises estatísticas e linguísticas demonstraram que há associação mediana $\left(C^{*}=0,53231\right)$ entre a polissemia do verbo fazer e sentenças causativas, embora a polissemia reduza a probabilidade de construções causativas com esse verbo.

Palavras-chave: Verbos causativos. Sentenças causativas. Polissemia. Protótipo.

\section{INTRODUÇÃO}

A causatividade é um fenômeno associado à relação de causa-efeito. Esse fenômeno tem sido estudado em campos teóricos diversos, como a Filosofia e a Linguística. Na filosofia, a causalidade é entendida, em termos gerais, como o nexo entre duas coisas em virtude do qual a segunda coisa é univocamente previsível a partir da primeira (ABBAGNANO, 2007, p. 142). Na Linguística, a causatividade gerou estudos em diversas linhas como no Gerativismo, na Semântica Lexical e no Funcionalismo. Esse fenômeno, de modo geral, pode ser entendido como 1) estruturas linguísticas formadas a partir de verbos causativos ou 2) situações causativas (que podem envolver outras categorias de verbos). Segundo Neves 
(2000), os verbos causativos são verbos transitivos em que o sujeito (agente ou causa) age sobre outro indivíduo (ou coisa), forçando-o a realizar algo ou a se tornar algo, de modo a estabelecer uma relação de causa-efeito. Por exemplo:

(1) João fez Maria limpar a casa.

Em (1), o sujeito da oração principal João (causa) age sobre Maria, fazendo esta executar a ação de limpar a casa (efeito), sendo que o verbo causativo fazer estabelece essa relação. Além disso, de acordo com Neves (2000), as sentenças construídas com verbos causativos, geralmente, são compostas por duas orações: uma principal e outra subordinada. Assim, em (1), há uma oração principal (João fez) e uma oração subordinada (Maria limpar a casa). Verbos como mandar, fazer, provocar, causar, assegurar, provar, cuidar, proibir são alguns exemplos de causativos em português. Já a situação causativa, mais estudada pelos filósofos, ocorre quando uma situação de causa-efeito é expressa, em uma estrutura sintética. Por exemplo:

(2) Pedrinho quebrou a xícara.

A sentença (2) é um exemplo de situação causativa, visto que o verbo quebrar é causativo, embora não forme sentenças causativas analíticas. Pela literatura tradicional, as sentenças analíticas são formadas a partir de verbos como fazer, mandar, deixar e causar. Este tipo de verbo, geralmente, é núcleo de uma oração principal que requer uma oração complementar, expressando assim as duas fases fundamentais da estrutura causativa: a fase Causadora (causa) e a Causada (efeito) (Bittencourt, 1995). Entretanto, a oração (2) também expressa uma relação de causa-efeito. A ação de quebrar, realizada por Pedrinho, muda o estado da xícara. Portanto, Pedrinho é a causa e a xícara quebrada é o efeito da ação executada por Pedrinho.

Enquanto os filósofos se interessam mais pelas situações causativas (por serem fenômenos gerais de causa-efeito), os linguistas privilegiam as construções causativas, buscando muitas vezes classificá-las. Segundo Bittencourt (1995), em português brasileiro (doravante $\mathrm{PB}$ ), há três tipos de sentenças causativas: a causativa analítica, a causativa semi-analítica e a causativa sintética. A sentença 
causativa analítica é construída com duas orações, sendo que, na oração principal, há um verbo causativo e, na oração subordinada, há geralmente um verbo no infinitivo. Assim, há um agente (ou causa) que age sobre outro(a), que, por sua vez, desencadeia um efeito. Vejamos:

(3) Gilberto mandou João sair da sala.

A sentença (3) é um exemplo de causativa analítica, pois há uma oração principal com um verbo causativo que expressa a causa (Gilberto mandou) e há uma oração complementar (João sair da sala) com um verbo no infinitivo que expressa o efeito. Assim, é estabelecida a relação de dependência entre as ações, pois a causa encontra-se na oração principal e o efeito na oração subordinada. Já a causativa semi-analítica, que apresenta pequena diferença em relação à analítica, também é composta por duas orações, sendo a oração principal formada a partir de um verbo causativo. Nessa estrutura, porém, há um agente (ou causa) que age sobre outro(a) - o afetado - um pronome oblíquo, o que a caracteriza como uma categoria distinta da causativa analítica. Vejamos:

(4) Os problemas no joelho me fizeram desistir do futebol.

A sentença (4) é um exemplo de causativa semi-analítica. A oração principal (Os problemas no joelho me fizeram) também possui um verbo causativo e a oração subordinada (desistir do futebol) um verbo no infinitivo. Contudo, o pronome oblíquo me é afetado tanto pelo verbo da oração principal (fazer) quanto pelo verbo da subordinada (desistir). Esse tipo de relação não está presente na causativa analítica, que é o tipo de construção causativa mais prototípica, sendo estudada por linguistas de diversas tendências teóricas. Por fim, a causativa sintética é uma estrutura linguística diferente das causativas analítica e semi-analítica, já que se trata de um período simples formado sem um verbo causativo. Por exemplo:

(5) O tio correu os meninos do quarto.

A sentença acima é um exemplo de causativa sintética e apesar de não ter verbo causativo, estabelece uma relação de causa-efeito, que também não se 
confunde com uma situação causativa. Na realidade, a causa é explicitada (O tio), mas o efeito é pressuposto (os meninos correram), já que há evidências do verbo fazer em um nível subjacente. Dito de outra maneira, a sentença (5) pode ser entendida como "O tio fez os meninos correrem do quarto", já que o verbo fazer não é expresso na forma fonológica, mas apenas na forma lógica. Por essa razão, os gerativistas (HALE; KEYSER, 1993, 2002; CHOMSKY, 1995; dentre outros) defendem que verbos como fazer são considerados verbos leves e, além disso, verbos causativos. Para Hale e Keyser (2002), os verbos leves são verbos semanticamente vazios. Assim, nessas construções, o componente semântico será realizado a partir da ligação a um nominal. Por exemplo, "Dar uma olhada” (= olhar) e "Fazer uma caminhada" (= caminhar).

A relação de causatividade, por ser tratada a partir de diferentes perspectivas, tanto na Linguística quanto na Filosofia, é entendida de modos diversos, não havendo consenso sobre estar relacionada à Sintaxe, à Semântica, à Pragmática ou a combinação dessas áreas. Para Arrais, citando Shibatani (1976), a situação causativa tem duas proposições na estrutura semântica subjacente, uma proposição-causa e outra proposição-efeito, geralmente resumidas em uma única proposição, com apenas um verbo, na estrutura de superfície. Já Comrie (1989) defende que há aspectos sintáticos (relacionados à natureza do verbo causativo) e aspectos semânticos (relacionados ao agente causador), que resultam na estrutura das sentenças causativas.

Nesse contexto, é notável a presença de elementos semânticos que motivam a construção e a interpretação de sentenças causativas em PB, o que nos levou a investigar a polissemia relacionada ao verbo fazer. A polissemia é um fenômeno semântico muito discutido por linguistas e filósofos desde a antiguidade. De acordo com Batoréo (2009), essa problemática já foi discutida pelos Estoicos e por Aristóteles. Contudo, segundo a autora, só no início do século $\mathrm{XX}$, o linguista francês Michel Bréal cunhou o termo polissemia, referindo-se a estudos sobre a "multiplicação de sentidos das palavras".

Silva (2003) defende que a polissemia é um fenômeno de categorização prototípica, uma vez que o protótipo é o melhor representante de uma dada categoria, por ser central, típico e possibilitar a organização dos conceitos (CANÇADO, 2008). Assim, os vários usos de um item são relacionados a um centro prototípico, que apresenta semelhanças familiares com cada um deles. Por exemplo, 
ao investigar as estruturas semânticas de um verbo, como deixar (ex. deixar o trabalho, deixar a faca na mesa, deixar a visita entrar em casa etc.), é necessário analisar o objeto direto, o objeto indireto e outras estruturas. No entanto, a estrutura e o uso desse verbo, geralmente, estão relacionados aos sentidos de abandonar ou permitir. Isso evidencia que o verbo deixar, embora expresse mais de um sentido, apresenta significados que se relacionam entre si, ou seja, fazem parte de uma mesma categoria radial.

Silva (2003) argumenta também que a polissemia é um fenômeno aparentemente simples, entretanto é um conceito problemático, visto que é intrinsecamente instável. $\mathrm{O}$ autor argumenta que para definir polissemia é necessário distinguir conceitos como vaguidade (vagueza), indeterminação e especificações de um mesmo sentido. Por exemplo, o ato de comer pode ser realizado por colher ou garfo, porém, se esse ato pode ser feito por mais de um instrumento, por que isso não é entendido como polissêmico? O autor questiona como é possível definir essas propriedades, a fim de distinguir se a relação é polissêmica ou homonímica. Para o autor, a polissemia só pode ser definida a partir da definição de homonímia, visto que esta expressa diferentes sentidos por um mesmo nome (por exemplo, banco (instituição bancária ou espécie de assento). Desse modo, para a definição desses conceitos, o pesquisador defende que é necessário investigar questões como a diferenciação e a relação entre os sentidos.

Já para llari (2002), a polissemia pode ser definida como sentidos diferentes de uma mesma palavra, os quais se relacionam a um sentido básico, comum. Nesse ponto, difere da homonímia, em que um item lexical possui sentidos distintos, como, por exemplo, o item banco (instituição bancária ou espécie de assento). Assim, o autor defende que na polissemia uma só palavra expressa mais de um sentido, mas há um contínuo entre esses vários sentidos. Já na homonímia, é necessária mais de uma palavra, visto que há descontinuidade de sentidos nas palavras homônimas. Portanto, a definição de polissemia, apesar de problemática, é consensual por se tratar de fenômeno semântico, no qual um item lexical geralmente apresenta dois ou mais sentidos que se relacionam entre si. Desse modo, como o verbo fazer é um verbo causativo por excelência e ao mesmo tempo um item polissêmico, objetivamos investigar se a polissemia motiva (facilita ou dificulta) a construção de causativas analíticas e semi-analíticas. 


\section{METODOLOGIA}

Primeiramente, fizemos um levantamento geral dos verbos causativos e, para isso, tomamos como referência a lista apresentada por Neves (2000, p. 41), conforme demonstrado a seguir. Para nos certificar do grau de polissemia do verbo fazer, quantificamos as acepções ${ }^{3}$ desse verbo e também o número de acepções dos demais verbos causativos, utilizando um dicionário (FERREIRA, 2004). Por meio desses procedimentos, verificamos que o verbo fazer apresenta, no mínimo, quatro vezes mais acepções que os demais verbos causativos, evidenciando alta polissemia ${ }^{4}$. Assim, chegamos as seguintes conclusões: Os verbos causativos assegurar (8 acepções), causar (1 acepção), cuidar (10 acepções), provar (14 acepções) e provocar (12 acepções) foram classificados como menos polissêmico (polissêmico), ao passo que o verbo fazer (58 acepções) como mais polissêmico (+ polissêmico).

Após classificarmos os verbos causativos, buscamos definir as categorias de mais causativo (+ causativo) e menos causativo (- causativo), de acordo com o referencial teórico apresentado na "introdução". Como decidimos trabalhar apenas com as causativas analíticas e semi-analíticas, apenas esses dois tipos de estruturas foram classificadas como mais causativa (+ causativa). Quando os verbos eram utilizados de outras formas, inclusive em situações causativas e causativas sintéticas, classificamos as construções como menos causativas (- causativa). Para que nosso trabalho fosse empírico, todas as sentenças em estudo foram extraídas do Corpus do Português (45 milhões de palavras), organizado por Mark Davies e Michael Ferreira (Corpus do Português). Como esse corpus é bastante diversificado, adotamos o critério de selecionar sempre as primeiras construções linguísticas encontradas, até preenchermos 80 (oitenta) ocorrências de cada grupo (+ polissêmico Versus - polissêmico). Abaixo, encontram-se os passos metodológicos:

\subsection{Passo 1: Análise de sentenças construídas com o verbo fazer (+ polissêmico)}

Foram selecionadas 80 sentenças com o verbo fazer, sendo todas as estruturas no mesmo tempo verbal (pretérito perfeito do indicativo), conjugado em pessoas verbais diferentes. Desse modo, foram selecionadas 20 sentenças com 0 
verbo fazer conjugado na primeira pessoa do singular; 20 sentenças com o verbo fazer conjugado na terceira pessoa do singular; 20 sentenças com o verbo fazer conjugado na primeira pessoa do plural e 20 sentenças com o verbo fazer conjugado na terceira pessoa do plural, totalizando 80 sentenças. Assim, as 80 ocorrências com o verbo fazer (+ polissêmico) foram classificadas como causativas (+ causativa) ou não causativas (- causativa).

\subsection{Passo 2: Análise de sentenças construídas com os verbos assegurar, causar, cuidar, provar e provocar (- polissêmico)}

Foram selecionadas 16 sentenças com o verbo assegurar, 16 com o verbo causar, 16 com o verbo cuidar, 16 com o verbo provar e 16 com o verbo provocar, totalizando 80 sentenças. O mesmo critério de seleção do Passo 1 foi aplicado no Passo 2, já que isso seria uma forma de garantir homogeneidade entre os dois grupos, exceto no que se refere à polissemia. Assim, as 80 ocorrências com esses verbos causativos (- polissêmico) foram classificadas como causativas (+ causativa) ou não causativas (- causativa).

\subsection{Passo 3: Aplicação do Teste Qui-Quadrado}

Após a quantificação de quantas sentenças causativas foram encontradas, tanto com o verbo fazer quanto com os demais verbos, foram aplicados o teste estatístico qui-quadrado e o coeficiente de contingência modificado (BARBETTA, 2004). O teste qui-quadrado foi utilizado para verificar se havia associação entre variáveis categóricas, no caso a polissemia associada ao verbo fazer e a construção causativa (analítica e semi-analítica). Já o coeficiente de contingente foi utilizado para examinar o grau de associação, pois quanto mais próximo de 1, maior a associação, e, quanto mais próximo de 0 , menor. Em síntese, essas análises estatísticas ${ }^{5}$ nos possibilitaram verificar se a polissemia do verbo fazer influencia no número de sentenças causativas, construídas com esse verbo. 


\section{RESULTADOS}

Conforme dito na seção Metodologia, foram selecionadas 80 sentenças com o verbo polissêmico fazer e 80 com os demais verbos não polissêmicos (assegurar, causar, cuidar, provar e provocar), conforme a Tabela 1. Entre as sentenças construídas com o verbo fazer, apenas 3 eram causativas, enquanto 77 não eram, o que corresponde a 3,75\% e 96,25\%, respectivamente. Já entre as sentenças construídas com os verbos assegurar, cuidar, provar e provocar, 29 delas eram causativas e 51 não eram causativas, o que corresponde a 36,25\% e 63,75\%, respectivamente. Portanto, a estatística descritiva nos possibilita perceber elevada desproporção entre os dois grupos (+ polissêmico Versus - polissêmico), já que a frequência de construções causativas com o verbo fazer é bem inferior. Em seguida, aplicamos o teste qui-quadrado para verificar se essa diferença era estatisticamente significativa e não apenas resultado de associações casuais.

Tabela 1 - Frequências e porcentagens de causativas em função da polissemia

\begin{tabular}{l|c|c|c|c}
\hline & \multicolumn{2}{|c|}{$\begin{array}{c}\text { (+) Polissêmico } \\
\text { (fazer) }\end{array}$} & \multicolumn{2}{c}{$\begin{array}{c}\text { (-) Polissêmico } \\
\text { (assegurar, causar, cuidar, } \\
\text { provar e provocar) }\end{array}$} \\
\hline $\begin{array}{l}\text { Tipo de Construção } \\
\text { Frequência }\end{array}$ & Percentagem & $\begin{array}{c}\text { Frequên } \\
\text {-cia }\end{array}$ & Percentagem \\
\hline $\begin{array}{l}\text { (+) causativa } \\
\text { (analíticas e semi- } \\
\text { analíticas) }\end{array}$ & 3 & $3,75 \%$ & 29 & $36,25 \%$ \\
\hline (-) causativa & 77 & $96,25 \%$ & 51 & $63,75 \%$ \\
\hline \multicolumn{1}{c|}{ Total } & 80 & $100,00 \%$ & 80 & $100,00 \%$ \\
\hline
\end{tabular}

Conforme pode ser observado na Tabela 2, a seguir, o elevado qui-quadrado $(26,41)$ demonstra que há associação entre polissemia e causatividade, ou seja, a polissemia associada ao verbo fazer difere esse verbo causativo dos outros verbos causativos que não são polissêmicos. O p-valor, por sua vez, demonstra que a probabilidade dessa associação ser casual, falsa ou espúria, é muito pequena (tendendo a $0 \%$ ). Em resumo, os números obtidos por meio do cálculo qui-quadrado e do $p$-valor demonstram haver associação entre a polissemia do verbo fazer e a causatividade. A partir do cálculo do coeficiente de contingência modificado $(0,53)$, foi possível perceber que a associação é mediana. Portanto, a partir desses resultados, pudemos observar que quando os verbos causativos não são 
polissêmicos (verbos como assegurar, causar, cuidar, provar e provocar), a chance de aparecerem em uma construção causativa é mais elevada, uma vez que a polissemia do verbo fazer parece "atrapalhar" a construção de sentenças causativas.

Tabela 2 - Resultados do teste qui-quadrado

\begin{tabular}{l|l}
\hline \multicolumn{1}{c|}{ Estatísticas } & \multicolumn{1}{c}{ Valores } \\
\hline Qui-quadrado & 26,41 \\
\hline P-valor & 0.000000277 \\
\hline $\begin{array}{l}\text { Coeficiente de contingência } \\
\text { modificado }\end{array}$ & 0,53231 \\
\hline
\end{tabular}

\section{DISCUSSÃO}

Apesar de pressupormos que haveria um número substancial de sentenças causativas com o verbo fazer, por se tratar de um verbo prototipicamente causativo e polissêmico, os resultados revelaram o oposto, pois houve um número mais expressivo de sentenças causativas com os verbos causativos não polissêmicos (assegurar, causar, cuidar, provar e provocar). Entretanto, pudemos comprovar estatisticamente que houve associação entre a polissemia do verbo fazer e a frequência desse verbo em sentenças causativas, embora essa associação fosse inversa. Em outras palavras, pressupomos que a polissemia associada ao verbo fazer facilitaria a construção de sentenças causativas (analíticas e semi-analíticas), mas a polissemia, na verdade, parece diminuir a probabilidade dessas construções. Segundo Barbosa da Silva (2006), o verbo fazer, por ser polissêmico, pode apresentar as seguintes características e significados:

a) Fazer com o sentido [+ prototípico] (Sujeito/agente + Fazer (prototípico - "produzir algo por meio de determinada ação"). Ex.: Eu fiz a cerca do quintal.

b) Fazer com sentido [- prototípica] (Sujeito/paciente + Fazer (prototípico "produzir algo por meio de determinada ação"). Ex.: Maria fez uma cirurgia.

c) Fazer em processo de lexicalização. Ex.: O João fez uma viagem para a Europa. $\rightarrow$ Fazer viagem $=$ viajar . 
d) Fazer curinga (vicário), quando esse verbo pode ser substituído por outro. Ex.: Eu fiz arroz ontem. $\rightarrow$ fazer $=$ preparar, cozinhar. Nesse caso, o arroz já está pronto, assim o verbo fazer não é empregado no sentido de produzir por meio de determinada ação, mas de preparar ou cozinhar o alimento.

Conforme apresentado acima, o verbo fazer pode ser usado no sentido de 1) produzir algo por meio de determinada ação (como fazer uma cerca), 2) ser usado de forma lexicalizada (como fazer viagem = viajar; fazer planos = planejar) e 3) ser utilizado no sentido amplo de produzir, substituindo outros verbos (como fazer arroz = cozinhar; fazer faculdade $=$ estudar). Desse modo, é notável que os vários sentidos apresentados pelo verbo fazer possuem relação polissêmica, visto que todos esses sentidos estabelecem relação entre si, pois expressam ideia de produzir ou executar algo, independente de ser algo concreto ou abstrato. Nesse contexto, a hipótese aventada neste artigo, inicialmente, se devia ao fato de pensarmos que a polissemia associada ao verbo fazer motivaria a construção de sentenças causativas (analíticas e semi-analíticas), a partir de duas orações, uma principal com o verbo causativo fazer (expressando causa) e uma subordinada (expressando efeito). No entanto, sentenças causativas analíticas e semi-analíticas com o verbo fazer, como os exemplos (6) e (7), foram menos frequentes do que as situações causativas.

(6) [...] eu fiz publicar a convocação no Diário Oficial deste sábado. (Corpus do Português)

(7) [...] minha mãe, antes de falecer, me fez prestar um concurso. (Corpus do Português)

As sentenças acima, retiradas do Corpus do Português, são exemplos de sentenças causativas. A sentença (6) é uma sentença causativa analítica, pois é formada com um verbo causativo fazer, em que há uma oração principal (eu fiz) que expressa causa e uma oração subordinada (publicar a convocação no Diário Oficial deste sábado) que expressa efeito. Já a sentença (7) é um exemplo de sentença causativa semi-analítica, pois há um verbo causativo fazer na oração principal (minha mãe me fez), que expressa causa, e uma oração subordinada (prestar um concurso); que expressa efeito, além da presença do oblíquo me. Conforme dito 
previamente, há um número muito pequeno, nos dados analisados, de sentenças causativas com o verbo fazer, visto que foram encontradas apenas 3 ocorrências. No entanto, comprovamos que, nesses dados, quase 1/3 das orações com o verbo fazer foram utilizadas em situações causativas, que também expressam relações de causa-efeito.

(8) fez uma caixa e pintou. (Corpus do Português)

(9) fizemos uma ampla reforma física na Academia de Policia Civil. (Corpus do Português)

A sentença (8) expressa relação de causa-efeito, visto que alguém (causa) agiu sobre o mundo, construindo uma caixa e a pintando (efeito), modificando o estado do objeto-de-mundo. Embora o agente não esteja foneticamente realizado, é possível deduzi-lo logicamente por acarretamento, já que a posição de sujeito do verbo fazer geralmente é preenchida pelo papel temático agente (ou causa). Em (9) ocorre algo semelhante, pois embora o agente (causa) não seja expresso sintaticamente, a ação desencadeada pelo sujeito modifica o estado da Academia de Policia Civil, que é reformada (efeito). Desse modo, é possível notar que o uso do verbo causativo fazer, que poderia ser utilizado em sentenças causativas, perde espaço para uma situação causativa. Dito de outra forma, a construção de situações causativas sugere ser esta uma forma econômica e prática de expressar relações de causa-efeito, já que a sentença causativa é bem complexa (um ser age sobre outro ser ou objeto, modificando o estado deste, havendo necessidade de oração subordinada etc.).

Nesse contexto, compreendemos por que o uso da situação causativa, em relação à sentença causativa propriamente dita, é um questionamento forte na filosofia. Segundo Cottingham (1995), René Descartes, baseado em Aristóteles, defendia que a causa transmite propriedades ao efeito, sendo que o efeito advém da causa. Desse modo, há uma relação de dependência entre causa e efeito, já que 1) não existe efeito sem causa e 2) toda consequência necessariamente apresenta um efeito associado. Essas relações de causa-efeito ocorrem no mundo e, naturalmente, se expressam na linguagem por meio das relações temáticas. As concepções Cartesianas de causalidade explicariam porque na posição de sujeito (ou na oração principal da causativa) geralmente há um papel temático de agente 
(causa), enquanto na posição de objeto (ou na oração subordinada) um paciente (efeito).

Já para o filósofo David Hume, causa-efeito é uma relação de contiguidade experiencial e empírica, não se tratando de forças mecânicas e matemáticas que ocorrem no mundo. Hume (1739), citado por Aguiar (2008), propunha que, na relação de causalidade, um objeto precedente contiguamente ao outro, expressa uma ideia que, por sua vez, facilita a formação de outra ideia, aparentando ser uma dependente da outra. Assim, no conceito de Hume, uma experiência que antecede outra é a ela associada como uma relação de causa-efeito, pois é essencial que um evento preceda outro. Portanto, a causatividade percebida na linguagem não seria o reflexo das relações de causa-efeito presentes no mundo, mas sim associações de ideias que relacionam empiria e experiência.

Por se tratar de uma discussão filosófica, Aguiar (2008) questiona as estipulações temporais que permeiam 0 desenvolvimento da causa e o desencadeamento do efeito. A discussão proposta por Descartes e Hume é essencial para a compreensão da causatividade, já que os estudos linguísticos encontram-se, direta ou indiretamente, fundamentados na filosofia da linguagem. Leite (2012) ressalta que Bertrand Russell (1913) é o único filosofo que contesta a relação de causalidade como entendida classicamente. Para Russell (1913), um evento $A$, determinante, pode ocorrer antes, depois e até mesmo simultaneamente a um evento B. Assim, para Russell (1913) não há relação de causa-efeito, visto que fatos empíricos podem ocorrer sem implicar e sem manter dependência uns com os outros. Portanto, é possível presumir que a polissemia associada ao verbo fazer possibilita a expressão de relações de causa-efeito mais facilmente, sem demandar grandes "esforços" cognitivos dos participantes da comunicação.

Assim, o verbo fazer, em relação aos demais verbos causativos, além de polissêmico, pode ser considerado o protótipo da categoria descritiva "causatividade", basicamente por quatro razões. Primeiro, ele pode ser utilizado em construções relativamente complexas, como as causativas analíticas ("João fez Maria largar o serviço"), que requer oração subordinada e verbo no infinitivo. Segundo, esse verbo poder ser utilizado em construções causativas semi-analíticas (“João me fez perder o almoço"), um subtipo que também apresenta certa complexidade, por haver pronome oblíquo etc. Terceiro, ele pode ser utilizado em situações causativas ("João fazia bolos", "O furacão fez uma catástrofe" etc.), que 
geralmente seguem a estrutura canônica do português (sujeito, verbo e objeto). Por fim, segundo alguns autores (BITTENCOURT, 1995; SILVA 2009), ele está implícito nas causativas sintéticas ("Fernanda cortou o cabelo", ou seja, "Fernanda fez alguém cortar seu cabelo").

Talvez essa discussão sobre causalidade, polissemia e prototipicidade explique o número expressivo de situações causativas com o verbo fazer, em relação aos demais verbos causativos. O sujeito do verbo fazer pode alocar o papel de agente (ou causa) que engendra o evento causa, enquanto seu objeto direto aloca o papel temático de paciente (ou tema), que engendra o evento efeito. Portanto, na situação causativa, não há necessidade de um agente (ou causa) que aja sobre outro(a) que, por sua vez, modifique algo (ou alguém), tão pouco necessita de oração subordinada com verbo no infinitivo ou pronome oblíquo. Em outras palavras, produzir situações causativas com o verbo fazer é mais econômico cognitivamente que construir sentenças causativas (analíticas e semi-analíticas). Finalizando, a relação de causatividade, embora polêmica e pouco consensual, é aceita pela grande maioria das correntes filosóficas e linguísticas como importante objeto de estudo.

\section{CONCLUSÕES}

Ao analisarmos se a polissemia do verbo fazer interfere na frequência de sentenças causativas, chegamos à conclusão de que a polissemia influencia, mas também diminui as chances de sentenças causativas (analíticas e semi-analíticas) formadas com esse verbo. Desse modo, pudemos verificar que verbos causativos menos polissêmicos (assegurar, causar, cuidar, provar e provocar) aparecem com maior frequência em sentenças causativas. Foi possível depreender, ainda, que, apesar do número reduzido de sentenças causativas com o verbo fazer, esse verbo possibilita a construção de sentenças que expressam situações causativas. Em outras palavras, a grade temática do verbo fazer (agente-paciente, causa-paciente etc.) possibilita a construção de sentenças bem mais simples, que também expressam relações de causa-efeito. Por isso, pressupomos que a situação causativa, por possibilitar a formação de sentenças que expressam causa-efeito de forma mais econômica, torna-se mais viável e usual por exigir menos esforço cognitivo. Desse modo, mais estudos são necessários com a finalidade de investigar 
se a situação causativa vem substituindo as sentenças causativas e se outros verbos causativos têm sido lexicalizados de forma semelhante ao verbo fazer.

\title{
NOTAS
}

${ }^{1}$ Mestranda em Estudos Linguísticos pela Universidade Federal de Minas Gerais (UFMG), pósgraduada em Gramática da Língua Portuguesa pela Pontifica Universidade Católica de Minas Gerais (PUC Minas) e graduada em letras pela mesma instituição (Bolsista FAPEMIG). Endereço: Universidade Federal de Minas Gerais (UFMG), Av. Antônio Carlos, 6.627, Faculdade de Letras (FaLe), Sala 4035, Campus UFMG, Pampulha, CEP: 31270-901, Belo Horizonte, Minas Gerais. Tel: (31) 3409-5492. glendamilanio@hotmail.com

${ }^{2}$ Doutorando em Saúde Pública pela Universidade Federal de Minas Gerais (UFMG), mestre em Linguística Teórica e psicólogo pela mesma instituição. (Bolsista CNPq). Membro do Núcleo de Estudos Cognitivos no Discurso (NECODI) e do Estudo Longitudinal de Saúde do Adulto (ELSA/BRASIL). Endereço: Universidade Federal de Minas Gerais (UFMG), Av. Prof. Alfredo Balena, 190 - Faculdade de Medicina (FM), Hospital Borges da Costa, Projeto ELSA-BRASIL, Campus UFMG Saúde, CEP: 30130-100, Belo Horizonte, Minas Gerais. Tel: (31) 3409-9140. waf.ufmg@gmail.com

${ }^{3}$ Apesar de haver a possibilidade de encontrarmos palavras homônimas no levantamento do número de acepções para cada item lexical, consideramos essa quantificação a forma mais objetiva para classificar a relação de polissemia de cada verbo.

${ }^{4}$ Vale ressaltar que o verbo mandar também é um verbo causativo, mas que apresentou número considerável de acepções (19 acepções), por isso optamos por desconsiderá-lo; por ser bastante polissêmico.

${ }^{5}$ Essas estatísticas foram calculadas respectivamente no OpenEpi 2.3.1 (Disponível em: <http://www.openepi.com/OE2.3/Menu/OpenEpiMenu.htm>. Acessado em 28/12/2012) e no programa Microsoft Office Excel 2010, por introdução de fórmula apresentada por Barbetta (2004, p. 262).

\section{THE INTERFERENCE OF THE POLYSEMY OF THE VERB FAZER IN CAUSATIVE SENTENCES: AN LINGUISTIC AND COGNITIVE ANALYSIS}

\begin{abstract}
The goal of this paper was to investigate if the polysemy of the verb fazer ("to do") affects the frequency of the causative sentences (analytics and semi-analytics) constructed with this verb, having as theoretical framework the Theoretical Linguistics. In order to do so, we applied the "Chi-square test" and the "contingency coefficient modified", in order to compare the causative verb fazer (more polysemic) with other causative verbs less polysemic ("to assure", "to cause", "to care", "to prove" and "to provoke"). The statistical and linguistic analysis revealed a mid-
\end{abstract}


association $\left(C^{*}=0.53231\right)$ between the polysemy of the verb fazer and causative sentences, although the polysemy reduces the frequency of the causative constructions with this verb.

Keywords: Causative verbs. Causative sentences. Polysemy. Prototype.

\section{REFERÊNCIAS}

ABBAGNANO, N. Dicionário de filosofia. São Paulo: Martins Fontes, 2007.

AGUIAR, T. Causalidade e direção do tempo: Hume e o debate contemporâneo. Belo Horizonte: Editora UFMG, 2008.

BARBETTA, P. A. Estatística aplicada às ciências sociais. 5. ed. Florianópolis: Editora da UFSC, 2004.

BATORÉO, H. Entre dois fogos ou a pertinência do continuum entre polissemia e homonímia. Visão escalar na abordagem teórica em Linguística Cognitiva aplicada ao ensino do Português língua não-materna. In: Textos seleccionados. XXIV Encontro Nacional da Associação Portuguesa de Linguística. Lisboa: APL. 2009. p. 115-124.

BARBOSA DA SILVA, C. M. M. Transitividade verbal: uma análise funcional das manifestações discursivas do verbo fazer. Gragoatá, Rio de Janeiro, v. 17, p. 101$114,2006$.

BITTENCOURT, V. de O. Da expressão da causatividade no português do Brasil: uma viagem no túnel do tempo. 1995. Tese (Doutorado)-Pontifícia Universidade Católica de São Paulo, 1995.

CANÇADO, M. Manual de semântica: noções básicas e exercícios. Belo Horizonte: Editora UFMG, 2008.

CHOMSKY, N. The minimalist program. Cambridge: MIT Press, 1995.

COMRIE, Bernard. Causative constructions. In: Language universals and linguistic typology: syntax and morphology. 2. ed. University of Chicago Press: Chicago, 1989. p. 165-184.

COTTINGHAM, J. Dicionário Descartes. Rio de Janeiro: Jorge Zahar Editor, 1995.

DAVIES, M.; FERREIRA, M. (2006) Corpus do português (45 million words, 1300s1900s). Disponível em: http://www.corpusdoportugues.org. Acesso em: 27 dez. 2012. 
FERREIRA, A. B. Novo dicionário Aurélio da Língua Portuguesa. 3 ed. Curitiba: Editora Positivo, 2004.

HALE, K.; KEYSER, S. On argument structure and the lexical expression of syntactic relations. In: 1993. p. 53-110. . (Eds.). The view from building 20. Cambridge: MIT Press, 2002. . Prolegomenon to a theory of argument structure. Cambrigde: MIT Press,

ILARI, R. Introdução ao estudo do léxico: brincando com as palavras. São Paulo: Contexto, 2002.

LEITE, P. K. Causalidade e teoria quântica. Scientiae Studia, São Paulo, v. 10, n. 1, 2012. Disponível em: <http://dx.doi.org/10.1590/S1678-31662012000100007>. Acesso em: 27 dez. 2012.

MATEUS, M. H. M; BRITO, A. M. et al. Gramática da Língua Portuguesa.7. ed. Lisboa: Editorial Caminho, 2003.

NEVES, M. H. de M. Gramática de usos do português. São Paulo: Editora UNESP, 2000.

SHIBATANI , M . Causativization. In: York: Academic Press, 1976. v. 5. p. 239-294. (Ed.). Syntax and Semantics. New

SILVA, A. S. da. O sentido múltiplo: polissemia, semântica e cognição. In: FELTES, H. P. de M. (Ed.). Produção de sentido: estudos transdisciplinares, Caxias do Sul: Editora da Universidade de Caxias do Sul, 2003. p. 91-115.

SILVA, Y. R. B. As causativas sintéticas no português do Brasil: novas evidências a favor da estrutura bipartida do VP. 2009. 134f. Dissertação (Programa de Pósgraduação em Estudos Linguísticos/POSLIN)-UFMG, Belo Horizonte, 2009. 